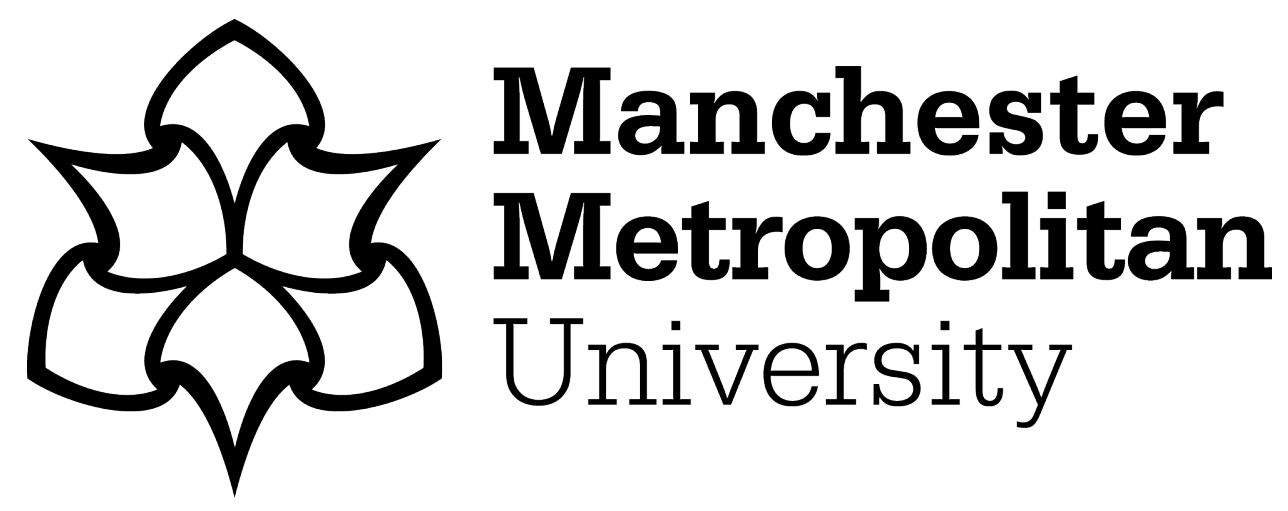

Abuarqoub, A, Abusaimeh, H, Hammoudeh, M, Uliyan, D, Abu-Hashem, MA, Murad, S, Al-Jarrah, M and Al-Fayez, F (2017) A survey on internet of things enabled smart campus applications. In: International Conference on Future Networks and Distributed Systems (ICFNDS 2017), 19 July 2017 - 20 July 2017, Cambridge, United Kingdom.

Downloaded from: https://e-space.mmu.ac.uk/620076/

Publisher: Association for Computing Machinery (ACM)

DOI: https://doi.org/10.1145/3102304.3109810

Please cite the published version 


\section{A Survey on Internet of Things Enabled Smart Campus Applications}

\author{
Abdelrahman Abuarqoub \\ Faculty of Information Technology \\ Middle East University \\ Jordan \\ AAbuarqoub@meu.edu.jo
}

\author{
Hesham Abusaimeh \\ Faculty of Information Technology \\ Middle East University \\ Jordan \\ HAbusaimeh@meu.edu.jo
}

\author{
Muhannad A. Abu-Hashem \\ Faculty of Information Techn`ology \\ Middle East University \\ Jordan \\ MAbuhashem@meu.edu.jo
}

\author{
Mohammad Hammoudeh \\ School of Computing, Mathematics \& \\ Digital Technology \\ Manchester Metropolitan University \\ United Kingdom \\ M.Hammoudeh@mmu.ac.uk \\ Sharefa Murad \\ Faculty of Information Technology \\ Middle East University \\ Jordan \\ smurad@meu.edu.jo
}

Mudhafar Al-Jarrah
Faculty of Information
Technology
Middle East University
Jordan
maljarrah@meu.edu.jo

\author{
Fayez Al-Fayez \\ College of Science \\ Majmaah University \\ Saudi Arabia \\ F.A.Alfayez@gmail.com
}

\begin{abstract}
The fictional future home, workspace or city, as predicted by science TV shows of the 1960s, is now a reality. Modern microelectronics and communication technologies offer the type of smart living that looked practically inconceivable just a few decades ago. The Internet of Things (IoT) is one of the main drivers of the future smart spaces. It enables new operational technologies and offers vital financial and environmental benefits. With IoT, spaces are evolving from being just 'smart' to become intelligent and connected. This survey paper focuses on how to leverage IoT technologies to build a modular approach to smart campuses. The paper identifies the key benefits and motivation behind the development of IoT-enabled campus. Then, it provides a comprehensive view of general types of smart campus applications. Finally, we consider the vital design challenges that should be met to realise a smart campus.
\end{abstract}

Permission to make digital or hard copies of all or part of this work for personal or classroom use is granted without fee provided that copies are not made or distributed for profit or commercial advantage and that copies bear this notice and the full citation on the first page. Copyrights for components of this work owned by others than ACM must be honored. Abstracting with credit is permitted. To copy otherwise, or republish, to post on servers or to redistribute to lists, requires prior specific permission and/or a fee. Request permissions from Permissions@acm.org.

ICFNDS '17, July 19-20, 2017, Cambridge, United Kingdom

(c) 2017 Association for Computing Machinery.

ACM ISBN 978-1-4503-4844-7/17/07...\$15.00

http://dx.doi.org/10.1145/3102304.3109810

\section{CCS CONCEPTS}

- Networks $\rightarrow$ Sensor Networks

- Hardware $\rightarrow$ Wireless integrated network sensors

- Information Systems $\rightarrow$ Information systems applications

\section{KEYWORDS}

Smart Campus, IoT, Smart Learning, Smart Buildings, Smart Grid, Waste and Water Management

ACM Reference format:

A. Abuarqoub, H. Abusaimeh, M. Hammoudeh, D. Uliyan, M. Abuhashim, S. Murad, M. Al-Jarrah, and F. Al-Fayez. 2017. A Survey on Internet of Things Enabled Smart Campus Applications. In Proceedings of ICFNDS '17, July 19-20, 2017, Cambridge, United Kingdom, 7 pages. DOI: $10.1145 / 3102304.3109810$

\section{INTRODUCTION}

After the proliferation of processors, wireless connectivity, smartphones and social networking, connecting electronic devices is the next generation of the Internet: the Internet of Things (IoT). According to Gartner [1] and ABI research [2], there will be around 26 to 30 billion devices connected to the Internet by 2020 . IoT aims at making our daily lives devices and appliances less sophisticated, autonomous, flexible and highly reachable at any time, from anywhere, to any user across the world. In IoT, smart objects such as home appliances, vehicles, houses, supply chain items, and containers will have digital identities and they will be context aware to sense the 
environment around them and seamlessly interact with each other. The basic notion of the IoT is that objects around us will be connected to the Internet to provide control and contextual services. Hence, IoT transforms the everyday physical objects that surround us into an ecosystem of information that will enrich our lives. Smart objects return useful information and use it in various applications during the objects' life cycle.

Objects in IoT are made smart through embedding intelligence using some innovational technologies, such as Wireless Sensor networks (WSNs) and mobile communication technology [3-7]. Smart objects would not be possible without sensors. Sensors monitor and detect changes in the surrounding environment, such as, motion, temperature, pressure, light, vibration, or acceleration. Sensors help in turning billions of objects into data generating "things" that can report their status to a specific base station. These billions of objects are required to have unique identifications. To satisfy this requirement, Radio Frequency IDentification (RFID) technology provides a suitable platform, in which an RFID tag with a unique identification is attached to each object in the IoT. To handle the unique identification of the billions of objects expected to be connected in the IoT, a 128-bit IPv6 addressing scheme has been adopted to accommodate about 340 undecillion addresses.

IoT technology indeed finds application in many different domains, such as home automation [8], healthcare monitoring [9, 10], traffic control [11], smart vehicles [12], smart grids [13], smart warehousing [14], smart cities [15], and smart campuses [16]. In fact, the smart campus came out of the concept of smart cities by applying the principles of smart cities to the operation of the campus. Smart campus is an emerging industry, with myriad solutions already adopted by several universities all over the world. Smart campuses are developed on the basis of digital campuses. Compared with traditional digital campus, smart campus provides services in a timely manner, reduces effort and cut operational costs. Smart campus implies that the institution will adopt advanced technologies to automatically control and monitor facilities on campus and provide high quality services to the campus community, i.e., students and staff. This lead to increasing the efficiency and responsiveness of the campus, and having better decision making, space utilization and students experience.

Several architectures to smart campus have been proposed with different goals $[17,18]$. Most of these architectures have three main layers: perception layer, network layer, and application layer. The bottom layer accommodates sensors to collect sensory data about the monitored phenomena. In the middle layer, data aggregation, filtering, fusion, and information extraction take place. In the top layer, servers or a cloud are used to store and retrieve data.

In the past decade, many initiatives have been put in place with a view to improve campuses services. For instance, Birmingham City University invested $£ 260$ million in a major campus development as part of a smart campus scheme involving multiple sites and structures [19]. They were able to achieve annual energy cost savings of $£ 140$ thousand and $40 \%$ reduction in $\mathrm{CO} 2$ emissions. The University of Glasgow is planning to invest $£ 800$ million in order to transform and expand their campus [19]. They are considering changes in technology learning, and cost savings. The focus is on making the university a more sustainable place for human exchange and interaction.

The objective of this paper is to address and discuss the existing smart IoT-based campus applications and systems. We describe the characteristics of smart campuses, emphasizing the main features and the major drawbacks. Additionally, we describe the challenges and outline some ideas and future research directions. The rest of the paper is organized as follows. Section 2 identifies the benefits and motivation behind smart campus applications. Section 3 provides an overview of general types of smart campus applications. Section 4 presents the current challenges facing the deployment of smart campus applications and highlights some future research directions. Finally, Section 5 concludes the paper.

\section{SMART CAMPUS: MOTIVATION AND BENEFITS}

Smart campuses has the potential to revolutionise the education system and offer the capability to enhance campus operating effectiveness, while delivering high quality services to the campus community. It provides an interactive and creative environment for students and faculty. Smart campuses offer the following advantages over traditional and digital campuses.

\subsection{Save costs and time}

Smart campus aims to promote smart energy, water and waste management through the installation of IoT-based services. Monitoring environmental conditions, such as temperature, humidity, pressure and natural lighting, have a direct impact on the energy consumption of buildings. For instance, environmental sensors at campus would control lights, turn them off periodically when there is no movement in the room. Moreover, smart grids will enable utilities or individuals to control when appliances are used, resulting in a greater ability for the consumer to determine when they want to use electricity, and at what price. This is expected to equalize the need for peak power, and spread the load more evenly over time.

\subsection{Automate maintenance}

Special loT sensors could be attached on every electrical device, which would be monitored by computer expert system. Hence, operation and maintenance team would be immediately notified to take appropriate action in a timely manner. This helps to improve the response time to operation by the maintenance team.

\subsection{Protect the environment}

Adopting IoT on campus would bring effective campus surveillance and real-time incidents warnings. For instance, perimeter access control systems measure who is coming in and going out and detect people in non-authorized areas. 
A Survey on Internet of Things Enabled Smart Campus Applications

Furthermore, sensors enables the detection of opened windows and doors to detect and prevent intruders.

\subsection{Achieve efficient parking}

Every working day, many students and staff members spend a frustrating amount of time to find an available car parking lot. This is not only a time-consuming and expensive, but it may also cause car traffic jams and increase pollution levels. Utilizing sensing technologies in parking lot and driveways would assist students and staff to find the nearest available car parking lot.

\subsection{Students and staff attendance}

Taking attendance is considered the most time consuming process especially in classes with large number of students. Automated attendance tracking for students and staff would save time and overcome the human errors in recording student attendance.

\subsection{Occupancy detection and tracking}

This service would provide students a map of the campus to assist them to navigate their way around the campus. For instance, the map could show students the areas that are the least crowded, the nearest canteen, the nearest toilets, available library seat, free lab stations or a certain room location.

\section{A SURVEY OF SMART CAMPUS APPLICATIONS}

\subsection{Smart Buildings}

Recent technological advances in the domains of architecture, communications, electronics, engineering and construction led to the emergence of smart buildings. Smart buildings are defined as buildings that are technologically aware, sustainable, healthy, meet the needs of occupants and business, flexible and adaptable to deal with change [20]. Hence, smart buildings are more efficient, comfortable, environmentally friendly and economic. Indoor comfort conditions and cost savings has been the main drivers behind smart buildings. In particular, control of the environmental parameters plays a crucial role in enhancing the quality of indoor living conditions and offers opportunities for reduction in energy consumption.

IoT can be a significant driving force to enhance building management systems. There is an increasing interest in IoTenabled real-time monitoring of environmental data to reduce energy consumption and to meet occupants comfort conditions. The work in [21] presents a prototype of a smart system for indoor office buildings. The proposed system takes into account several factors for improving the quality of the indoor environment, such as, thermal comfort, lighting, noise levels and natural ventilation. A prototype sensor system was developed based on the Arduino micro-controller, which can obtain and monitor environmental data in real-time. The developed node has a light-based alarm that uses lights to alarm user when the monitored area reaches a certain threshold. The system can
ICFNDS '17, July 19-20, 2017, Cambridge, United Kingdom

assist users in giving both real-time feedback and predictive control.

The smart buildings project of the University of Brescia [16] aims to demonstrate the feasibility of improving buildings energy efficiency in terms of heating, cooling, ventilation, lighting and status of electric equipment in an educational building, through the utilization of smart grid management, control systems and automation. The authors focus on the analysis of the possible actions to reduce the energy consumption of the building. They evaluate the efficiency of different measures that can be implemented to achieve such goal. Simultaneously, a design for an initial operational conditions monitoring system have been developed to increase the user's confidence and awareness on energy consumption. The energy reduction, renewable energy production, and the energy balance between generation and consumption have been evaluated. The results show enhancements in thermal properties of the building, while achieving significant reduction in energy consumption.

In [22], a web based building energy management system for university campuses, called CAMP-IT, was presented. CAMP-IT aims to reduce the campus energy consumption through optimising the operation of building's energy systems, while simultaneously improving the indoor living comfort in terms of air quality, thermal and visual comfort. The system monitors the energy load and performs energy analysis per building and for the campus as a whole. It achieved up to $30 \%$ reduction in energy usage.

Campus touring is another service that can be delivered to smart buildings using the IoT technology. This service is often accessed through using a smart phone application to help visitors navigate and find their ways in a campus that they are not familiar with. Visitors can visualise and obtain real-time feedback about the smart campus. Fu Jen Catholic University developed prototype mobile campus touring system [23]. Their system is capable of significantly changing the way in which information can be brought to people's daily activities. The evaluation of the system was based on a pilot testing; all users provided positive feedback about the mobile touring experience. However, the system can be further improved by integrating the social network function into the mobile touring system.

\subsection{Renewables and Smart Grid}

IoT technologies can aid in increasing the amount of energy from renewable sources, e.g., solar and wind, because they provide real-time responses to the natural fluctuations in energy generation associated with renewables [24]. While wind energy sources are usually located outside campuses, utilities could integrate IoT technology into local solar energy sources to capture clean energy more effectively.

IoT is often identified as a promising technology to improve the existing electric power systems, including generation, delivery, and utilization. This improvement could be through the transition to distributed "smart microgrids" that enable campuses to utilize local sources of renewable energy instead of coal- or diesel-powered remote generators. The next-generation 
of smart grids provides information and power as well as enhances efficiency and reliability through automated control and modern energy optimisation techniques to improve energy availability. A smart grid is able to monitor each point in the grid remotely and identify certain kind of appliances or industrial equipment connected to it. This helps in analysing the real-time load on the power system and to detect potential failures. Smart grid offers remote account connection services and tools that help in reducing monthly bills.

The authors of [13] present a smart sensor network architecture that can be installed inside a wide variety of buildings, such as university campuses, residential homes, industrial facilities or public buildings. The architecture allows inspecting an electrical installation in a non-intrusive way. It delivers standard measurements, but it is not limited to them; it also allows monitoring power quality disturbances events in detail, interactions between power lines, identify electrical equipment, correlate events between monitoring points, amongst others. Furthermore, the presented smart sensor network architecture is a powerful tool to evaluate an electrical system, which potentially can detect failures in the system. The architecture with its real-time calculations capacities and the big-data support in the network has promising interesting applications in the future smart grid. However, in order to detect power loses in the energy supply system, further analysis of renewable energy facilities such solar and wind power plants are needed.

There are several universities adopting microgrids within their campuses. In fact, some of these universities use the microgrid as a test-bed for researchers, corporations, innovators and entrepreneurs to investigate accelerating the innovations of new ideas related to smart grid generation, transmission, distribution, consumption and storage. For instance, Oregon State University integrated a synchrophasor architecture within their campus grid. The developed architecture provides better energy savings, consumption monitoring and alarm systems. However, the optimised results from the developed architecture are not realistic since this technology is new and needs further studies [25].

British Columbia Institute of Technology was selected to be the site of Canada's first microgrid aiming to provide opportunities for electrical utility companies and researchers to work together to develop architectures, protocols, and models of the evolving smart grid [26, 27]. The authors implemented a smart and accurate Fault Detection, Isolation and Service Restoration (FDISR) algorithm, based on a bidirectional communication infrastructure. The algorithm aims to support the campus power system operation in the presence and absence of the utility bus. This project enabled researchers to develop and validate technologies for co-generation, efficient transmission and distribution of electricity, load control, demand response, advanced metering and integration of clean energy sources into existing and future grids. Results showed that the tested power management strategy is efficient and that the proposed FDISR algorithm is accurate [28].
In the United States, Illinois Institute of Technology [29] took the initiative of building a self-healing and efficient smart grid in a research project entitled "Perfect Power". The project involved various parties who are interested in implementing smart grid systems, including the US department of energy, utility commissions, corporate campuses, hospitals and other institutions. Perfect Power is a self-healing, self-learning and self-aware smart grid that identifies and isolates faults, reroutes power to accommodate load changes and generation. It reduces consumption demand based on price signals, weather forecasts and loss of grid power. The project aims to create a smart grid model that can be used throughout the country, proving the reliable campus network distribution, reducing energy usage and emissions, reducing peak load by at least $20 \%$ and finally implementing a system that can operate in an islanded mode. Perfect Power is a powerful infrastructure that is considered as an optimum test-bed for researchers to study the development and integration of new ideas and technologies.

\subsection{Smart Learning}

Conventional learning systems have two main actors involved in the learning process, the educators who teach and the students who learn. Classical ways of content delivery required both actors to present at the same place and time. In addition to the restrictions related to coeducation, cross cultural and language barriers has always been a challenge to educators. All of these traditional learning barriers can be resolved by adopting a smart learning environment.

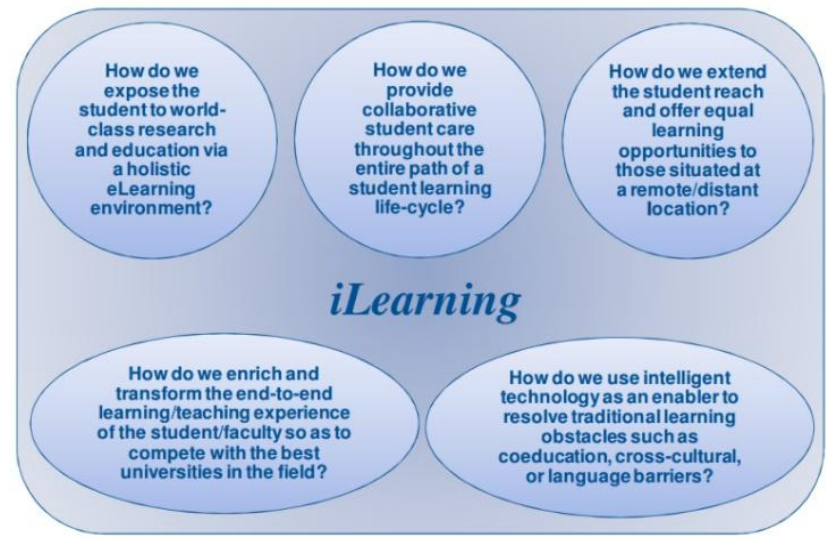

Figure 1: Smart Learning Key challenges, adopted from [30].

Smart learning environment provides a pervasive, interoperable and seamless learning architecture to connect, integrate and share three major dimensions of learning resources: learning collaborators, learning contents, and learning services [30, 31]. The smart learning environment typically includes: collaborative student care system, real time remote distance learning, user on demand course delivery and assessment, interactive cross- varsity lectures and online materials customized course program [32]. The smart learning environment creates several challenges, which are summarised in Figure 1. 
In the following, some of the scenarios where the IoT technology can be used in learning applications are presented:

3.3.1 Smart Attendance Systems. Taking attendance is considered the most time consuming process especially in classes with large number of students. RFID technology can perform automated and seamless attendance tracking for students and staff in order to save time and overcome human errors while recording student attendance. Smart attendance systems, such as [33, 34], uniquely identify individual students based on their unique tag identifiers. With such techniques, a report of attendees can be generated for a particular course with help of data centric student attendance database system.

3.3.2 Smart Laboratories. Employing IoT technology in laboratories conserves energy, saves time and maximises the utilization of available resources. The authors of [35] proposed a system to efficiently manage lab stations and air conditioners. Students use RFID tags, which are read while entering the smart lab in order to assign a computer to the student. The system tracks the usage of the labs and opens more labs when the demand is increasing. It uses mechanism to shutdown idle computers. Air conditioners are also turned on only when the temperatures reach a pre-set level. Consequently, efficient lab management and power saving are achieved.

3.3.3 Smart Libraries. Introducing IoT-based smart library system as a total alternative to existing library systems could have a huge potential in adding more value to their services and offering rich library experiences to users. Most libraries use RFID technology to protect books from being stolen, and for the issuing and returning of books. Smart libraries can automatically authenticate users, reply to their inquiries, issue and return books, and even locating books using location based service, for instance, delivering location details on the use's smartphone. The authors of [36] proposed an IoT based smart library system, which provides the luxury of fetching a book from its place with the assistance of an IoT-enabled interconnected system using a triangulation Wi-Fi based local positioning system and Near Field Communication (NFC) tags.

\subsection{Waste and Water Management}

Waste and water management are considered two essential and expensive services in buildings and campuses. Implementing IoT to manage these services can have a significant financial and environmental impact. Several works have been devoted to the study of waste management, e.g., [37-41], which generally propose equipping bins and waste trucks with sensor devices that collect real-time data for analysis. Extracted information is used for planning effective cleaning schedule, e.g., calculate economic waste collection route.

The authors of [37] proposed the Smartbin system that detects the trash levels in bins to optimise pick-up timings and appropriately plan disposal of different forms of waste. The system is designed to collect data and to deliver it through a wireless mesh network. The system employs a duty cycle technique to reduce power consumption and to maximise sensor nodes operational time. The Smartbin system was tested in an outdoor environment. Through the testbed, data was collected and applied to sense-making methods to obtain litter bin utilisation. With such information, litter bin providers and cleaning contractors are able to make better decision to help increase productivity and reduce costs.

Similarly, water management has direct impact on environmental sustainability. Reduction of water consumption, water reuse, and water harvesting processes are the three main pillars of sustainable water management. Several IoT approaches to water management have been proposed. Some approaches, such as, [42-44], focused on monitoring water consumption and water levels of campus reservoirs. The collected data is analysed and represented in visual graphs to enhance the readability. The authors of [45] presented automatic monitoring of the water grid by deploying sensor nodes along water pipes. Smart metering of water consumptions increases the users' awareness, improve the efficiency of the infrastructure management and provide early warnings of unusual events, e.g., detection of liquid presence outside tanks and pressure variations along pipes. However, most of the proposed water management approaches lack a generic model that standardized interfaces, integrates heterogeneous nodes and makes specific vendor equipment interoperable.

\section{SMART CAMPUS CHALLENGES AND FUTURE RESEARCH DIRECTIONS}

Before concluding this paper, this section provides a discussion about current challenges and future research directions in the area of IoT-enabled smart campus. This survey identified that most of the existing approaches to smart campus suffer from inherent problems that limit their applications. Firstly, adopting IoT on campus would result in using hundreds if not thousands of sensors, actuators and other objects, which may present an enormous burden to configure manually. Certainly, new ways of the automated configuration of IoT devices are needed to be thoroughly investigated. Secondly, the variety of sensing tasks and applications of IoT in smart campuses imposes the utilisation of heterogeneous IoT objects. This heterogeneity presents a huge hurdle in enabling collaborative sensing, hence, new interoperability standards are needed to integrate various devices into a single system. Additionally, there is a need for a standardised data format for description of data generated by IoT devices. Thirdly, it is expected that a large number of smart objects will be collaborating with each other to provide information about the surroundings, thus, an enormously huge volumes of data would be generated. Handling such big sensory data poses a major challenge as it requires advanced data fusion and optimisation techniques. If the data processing is to be performed in real-time, high speed communication links and powerful processing units will be needed. Finally, another important challenge of IoTenabled smart campuses is the power supply and energy efficiency. Objects can be mobile and hence it is difficult to connect them to power sources. Moreover, many objects are 
relatively small in size, and need to operate using self-sufficient energy source. Since radio communication is the most powerhungry operation [46], indoor and outdoor energy efficient communication mechanisms are essential.

Table 1: Smart Campus applications and their Benefits

\begin{tabular}{|c|c|}
\hline Application & Benefits \\
\hline 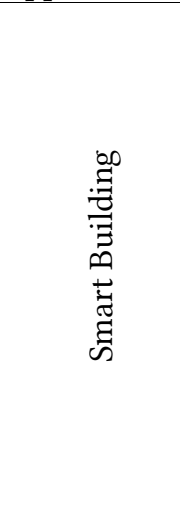 & $\begin{array}{l}\text { - } \begin{array}{l}\text { Improve the quality of } \\
\text { environment (lighting, thermal } \\
\text { natural }\end{array} \\
\text { comfort, noise levels, natur. } \\
\text { ventilation, etc.). } \\
\text { - } \text { Automate maintenance. } \\
\text { - } \text { Save time. } \\
\text { - } \text { Save cost. } \\
\text { - } \text { Achieve efficient parking. } \\
\text { - } \text { Protect the environment. } \\
\text { - } \text { Efficient parking. } \\
\text { - } \text { Perimeter access control. } \\
\text { - } \text { Occupancy detention and tracking. }\end{array}$ \\
\hline 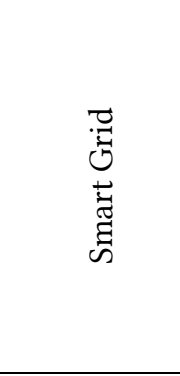 & $\begin{array}{l}\text { - } \text { Improve energy utilization and } \\
\text { - } \text { reduces monthly bills. } \\
\text { - } \text { Raise sustainability. } \\
\text { - } \quad \text { Allow analyzing the real-time load on } \\
\text { the power system. } \\
\text { - } \quad \text { Enhance reliability. } \\
\text { - } \quad \text { Detect potential failure. } \\
\text { - } \quad \text { Remote account connection services. }\end{array}$ \\
\hline 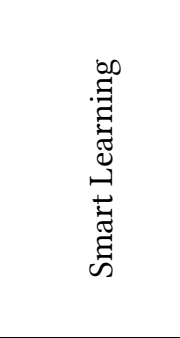 & $\begin{array}{l}\text { - } \text { Real time distance learning. } \\
\text { - } \text { On-demand course delivery. } \\
\text { - } \text { Automatic attendance tracking. } \\
\text { - } \quad \text { Cross-varsity lectures and online } \\
\text { materials. } \\
\text { - } \quad \text { Customized course programs. } \\
\text { - } \quad \text { Effective library management. } \\
\text { - }\end{array}$ \\
\hline 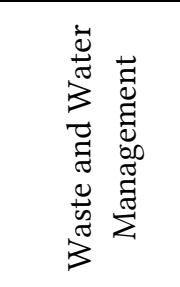 & 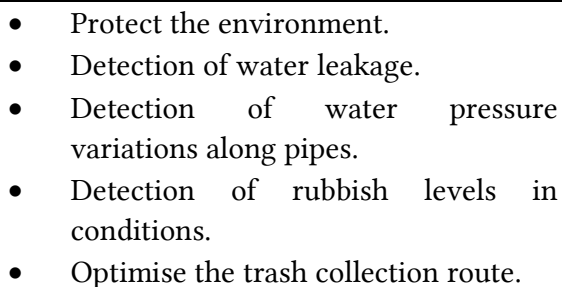 \\
\hline
\end{tabular}

Table 1 provides a summary of the smart campus applications and their benefits.

\section{CONCLUSION}

A smart campus can be realised using an IoT-enabled computing environment to establish an infrastructure for application to create and deliver value-added services through cooperative sensing of environment entities, i.e., humans, spaces, machines, etc. In this paper, we consider the vital design challenges hindering the development of IoT-enabled smart campus. We identify interoperability, information processing, system integration and efficient/reliable/high-speed communication as the main factors hindering the wide adoption of IoT to deliver smart campus. This paper makes one step toward a structured view on smart campuses as a computing paradigm for IoT applications. Our discussion is supported and referenced with numerous already implemented IoT-enabled campus application testbeds from such topical domains as renewable and smart grids, waste and water management and learning spaces, amongst others. We summarise the preliminary findings from the reviewed case studies and implementations. Finally, we discuss solutions to address the challenges identified in this domain. The discussed solutions can be already used in advanced IoT infrastructures.

\section{ACKNOWLEDGMENTS}

The authors are grateful to the Middle East University, Amman, Jordan for the financial support granted to cover the participation in the conference and the publication fee of this research article.

\section{REFERENCES}

[1] Gartner Gartner Says the Internet of Things Installed Base Will Grow to 26 Billion Units By 2020 http:// www.gartner.com/newsroom/id/2636073. City, 2016.

[2] ABIresearch More Than 30 Billion Devices Will Wirelessly Connect to the Internet of Everything in 2020 https://www.abiresearch.com/press/more-than-30-billion-deviceswillwirelessly-conne/. City, 2013.

[3] Abuarqoub, A., Hammoudeh, M. and Alsboui, T. An Overview of Information Extraction from Mobile Wireless Sensor Networks. City, 2012.

[4] Hammoudeh, M., Aldabbas, O., Mount, S., Abuzour, S., Alfawair, M. and Alratrout, S. Algorithmic construction of optimal and load balanced clusters in Wireless Sensor Networks. City, 2010.

[5] Abuarqoub, A., Hammoudeh, M., Adebisi, B., Jabbar, S., Bounceur, A. and Al-Bashar, H. Dynamic clustering and management of mobile wireless sensor networks. Computer Networks, 117(2017), 62-75

[6] Hammoudeh, M., Newman, R., Dennett, C., Mount, S. and Aldabbas, O. Map as a Service: A Framework for Visualising and Maximising Information Return from Multi-ModalWireless Sensor Networks. Sensors (2015), 22970-23003.

[7] Hammoudeh, M., Al-Fayez, F., Lloyd, H., Newman, R., Adebisi, B., Bounceur, A. and Abuarqoub, A. A Wireless Sensor Network Border Monitoring System: Deployment Issues and Routing Protocols. IEEE Sensors fournal, 17, 8 (2017), 2572-2582.

[8] Khan, M., Din, S., Jabbar, S., Gohar, M., Ghayvat, H. and Mukhopadhyay, S. C. Context-aware low power intelligent SmartHome based on the Internet of things. Computers \& Electrical Engineering, 52(2016), 208-222.

[9] A. Abuarqoub and Hammoudeh, M. Behaviour Profiling in Healthcare Applications Using the Internet of Things Technology. IRED fournals, 6, 3 (2016).

[10] Jabbar, S., Ullah, F., Khalid, S., Khan, M. and Han, K. Semantic Interoperability in Heterogeneous IoT Infrastructure for Healthcare. Wireless Communications and Mobile Computing, 2017(2017), 10.

[11] Kim, E. J., Jun, J. A. and Kim, N. S. The method of controlling traffic paths in IoT-based software defined network. City, 2016.

[12] Choi, Y., Han, S. I., Kong, S. H. and Ko, H. Driver Status 
Monitoring Systems for Smart Vehicles Using Physiological Sensors: A safety enhancement system from automobile manufacturers. IEEE Signal Processing Magazine, 33, 6 (2016), 2234.

[13] Morales-Velazquez, L., Romero-Troncoso, R. d. J., Herrera-Ruiz, G., Morinigo-Sotelo, D. and Osornio-Rios, R. A. Smart sensor network for power quality monitoring in electrical installations. Measurement, 103(2017), 133-142.

[14] Jabbar, S., Khan, M., Silva, B. N. and Han, K. A REST-based industrial web of things' framework for smart warehousing. The Journal of Supercomputing(2016), 1-15.

[15] Paul, A., Ahmad, A., Rathore, M. M. and Jabbar, S. Smartbuddy: defining human behaviors using big data analytics in social internet of things. IEEE Wireless Communications, 23, 5 (2016), 6874.

[16] De Angelis, E., Ciribini, A. L. C., Tagliabue, L. C. and Paneroni, M. The Brescia Smart Campus Demonstrator. Renovation toward a zero Energy Classroom Building. Procedia Engineering, 118(2015), 735-743.

[17] Hong-yan, K. Design and Realization of Internet of Things Based on Embedded System Used in Intelligent Campus International fournal of Advancements in Computing Technology(IfACT), 3, 11.37 (2011).

[18] Hirsch, B. and Ng, J. W. P. Education beyond the cloud:Anytimeanywhere learning in a smart campus environment. City, 2011.

[19] RiskUK Smart thinking at Birmingham City University drives sustainability and system interoperability. City, 2016.

[20] Alwaer, H. and Clements-Croome, D. J. Key performance indicators (KPIs) and priority setting in using the multi-attribute approach for assessing sustainable intelligent buildings. Building and Environment, 45, 4 (2010), 799-807.

[21] Habibi, S. Smart innovation systems for indoor environmental quality (IEQ). Fournal of Building Engineering, 8(2016), 1-13.

[22] Kolokotsa, D., Gobakis, K., Papantoniou, S., Georgatou, C., Kampelis, N., Kalaitzakis, K., Vasilakopoulou, K. and Santamouris, M. Development of a web based energy management system for University Campuses: The CAMP-IT platform. Energy and Buildings, 123(2016), 119-135.

[23] Chou, T.-L. and ChanLin, L.-J. Augmented Reality Smartphone Environment Orientation Application: A Case Study of the FuJen University Mobile Campus Touring System. Procedia - Social and Behavioral Sciences, 46(2012), 410-416.

[24] Brandie Nonnecke, Mia Bruch and Crittenden, C. IoT \& Sustainability: Practice Policy, and Promise white paper. Microsoft and CITRIS and the Banatao Institute, City, 2016.

[25] Chen, H., Song, J., Wagner, K., Harold, G. and Cotilla-Sanchez, E. Integrating synchrophasor technology with the Oregon State University campus smart grid project. City, 2014.

[26] Farhangi, H. Intelligent Micro Grid Research at BCIT. City, 2008.

[27] British_Colombia_Institute_of_Technology Microgrids: Energy Innovation for Our Future. City, 2017.

[28] Kamh, M. Z., Iravani, R. and Fouly, T. H. M. E.-. Realizing a smart microgrid \&\#x2014; Pioneer Canadian experience. City, 2012.

[29] Illinois_Institute_of_Technology http://web.iit.edu/. City, 2017.

[30] Svetlana, K. and YongIk, Y. Multimedia collaborative adaptation middleware for personalization E-learning. City, 2009.

[31] Zixue, C., Shengguo, S., Kansen, M., Tongjun, H. and Aiguo, H. A personalized ubiquitous education support environment by comparing learning instructional requirement with learner's behavior. City, 2005.

[32] Ng, J. White paper: The intelligent campus (icampus)," Etisalat BT Innovation Center (EBTIC), Tech. Rep., 2010. Etisalat BT Innovation Center, City, 2010.

[33] Sumita Nainan, Romin Parekh and Shah, T. RFID Technology Based Attendance Management System. IFCSI International Journal of Computer Science Issues, 10, 1 (2013), 516-521.

[34] Cheah Boon Chew, Manmeet Mahinderjit-Singh, Kam Chiang, WeiTan, Wei Sheng, Heikal Husin, Nurul Hashimah and Malim,
A. H. Sensors-enabled Smart Attendance Systems Using NFC and RFID Technologies. International fournal of New Computer Architectures and their Applications, The Society of Digital Information and Wireless Communications, 2015(2015), 19-28.

[35] Wang, H.-I. Toward a Green Campus with the Internet of Things the Application of Lab Management. Lecture Notes in Engineering and Computer Science, 2(2013).

[36] A. Larsan Aro Brian, L. Arockiam and Malarchelvi, P. D. S. K. An IoT based Secure Smart Library System with NFC Based Book Tracking. International fournal of Emerging Technology in Computer Science \& Electronics (IJETCSE), 11, 5 (2014).

[37] Folianto, F., Low, Y. S. and Yeow, W. L. Smartbin: Smart waste management system. City, 2015.

[38] Anagnostopoulos, T., Zaslavsy, A., Medvedev, A. and Khoruzhnicov, S. Top -- $k$ Query Based Dynamic Scheduling for IoT-enabled Smart City Waste Collection. City, 2015.

[39] Shyamala S.C, Kunjan Sindhe, Vishwanth Muddy and Muddy, V. Smart waste management system. International fournal of Scientific Development and Research (IFSDR), 1, 6 (2016), 23-230.

[40] Manasi Waikar, Rajat Lashkare, Rushabh Mutha and Vidwans, S. A Review on Solid Waste Management using SmartBin. International fournal of Innovative Research in Computer and Communication Engineering, 4, 11 (2016).

[41] Sakshi Goenka and Mangrulkar2, R. S. A Review Paper on Robust Waste Collection: Exploiting IoT Potentiality in Smart Cities. In Proceedings of the International Conference On Emanations in Modern Engineering Science and Management (ICEMESM-2017) (2017), [insert City of Publication],[insert 2017 of Publication].

[42] Robles, T., Alcarria, R., Martín, D., Morales, A., Navarro, M., Calero, R., Iglesias, S. and López, M. An Internet of Things-Based Model for Smart Water Management. In Proceedings of the Proceedings of the 2014 28th International Conference on Advanced Information Networking and Applications Workshops (2014). IEEE Computer Society, [insert City of Publication],[insert 2014 of Publication].

[43] Kudva, V. D., Nayak, P., Rawat, A., Anjana, G. R., Kumar, K. R. S., Amrutur, B. and Kumar, M. S. M. Towards a Real-Time CampusScale Water Balance Monitoring System. City, 2015.

[44] Mudumbe, M. J. and Abu-Mahfouz, A. M. Smart water meter system for user-centric consumption measurement. City, 2015.

[45] Gabrielli, L., Pizzichini, M., Spinsante, S., Squartini, S. and Gavazzi, R. Smart water grids for smart cities: A sustainable prototype demonstrator. City, 2014.

[46] Pottie, G. J. and Kaiser, W. J. Wireless integrated network sensors. Commun. ACM, 43, 5 (2000), 51-58. 